\title{
TECNOLOGIA ASSISTIVA COMO APOIO À AÇÃO DOCENTE
}

Gilda Pereira da Silva ${ }^{1}$, Adriano Rodrigues Ruiz ${ }^{2}$

${ }^{1}$ Mestre em Educação pela Universidade Paulista - UNOESTE. ${ }^{2}$ Docente do Mestrado em Educação na Universidade do Oeste Paulista - UNOESTE.E-mail: gilda-pereira@uol.com.br

\section{RESUMO}

O presente artigo teve por objetivo analisar a utilização de Tecnologia Assistiva na escolarização de crianças com Necessidades Educacionais Especiais (NEE). O método utilizado foi estudo de caso com abordagem qualitativa, cujos participantes foram uma aluna com NEE (paralisia cerebral), a professora da educanda, especialista da área de educação especial e oito professores que atuam na sala de aula do ensino regular. A coleta de dados ocorreu mediante a observação de 16 sessões na sala de aula do Apoio Especializado Itinerante. Os resultados indicaram que em atendimento especializado, a Tecnologia Assistiva permite a acessibilidade das crianças com necessidades especiais, com bom aproveitamento, a diferentes atividades educacionais; professores do ensino regular revelaram determinada resistência à inclusão, pela ausência de formação continuada extensiva aos docentes não especialistas; as Tecnologias Assistivas são pouco conhecidas pelos professores que atuam na sala de aula do ensino regular.

Palavras-chave: Tecnologia Assistiva; Inclusão; Atendimento especializado; Acessibilidade.

\section{INTRODUÇÃO}

A pesquisa relatada neste artigo originou-se de nosso percurso profissional que permitiu um olhar crítico, voltado para o que a escola indica como problemas de aprendizagem. Assim, buscamos auxílio nas concepções presentes em Piaget $(1974,1976)$, Vygotsky $(1989,1994,2007)$ e Wallon (1992), com o intuito de fundamentar teoricamente este estudo.

O uso da Tecnologia Assistiva pode favorecer a interação entre professor e aluno, trazendo para o meio educativo transformações no relacionamento professor-aluno-meio, colocando o docente em situação de reavaliação acerca de sua posição como agente socializador. Nesse sentido, a Tecnologia Assistiva surge como ferramenta de apoio que permite ao profissional incluir o conteúdo pedagógico de acordo com as necessidades dos alunos, com o intuito de promover aprendizagem colaborativa, num contexto que inspire diálogo, possibilitando ao educador mediar acessibilidade e inclusão.

A Tecnologia Assistiva compreende desde recursos simples até os mais sofisticados, com adaptações ao uso do computador, softwares e programas especiais que promovam acessibilidade e independência às pessoas com necessidades especiais (GALVÃO FILHO, 2001). Entretanto, faz-se necessário realizar ações que favoreçam o desenvolvimento e a construção de novos 
conhecimentos, baseando-se na diversidade de ideias e opiniões, explorando habilidades e competências.

Dessa forma, questiona-se: O professor, com base na variação de estratégias de ensino, pode mediar, pela ação docente, exploração e possibilidades de trabalhos na perspectiva do contexto educativo, podendo garantir a cada aluno um novo olhar sobre o que ensinar? Como, e para que ensinar?

\section{OBJETIVOS}

A presente pesquisa foi desenvolvida buscando-se respostas para os seguintes objetivos:

- Analisar possíveis contribuições da Tecnologia Assistiva utilizada por professora especializada para o desenvolvimento de uma criança com necessidades especiais;

- Investigar como professores do ensino regular percebem a Inclusão;

- Analisar como os professores do ensino regular entendem a Tecnologia Assistiva.

\section{METODOLOGIA}

Quanto à metodologia recorremos a abordagem qualitativa, com o estudo de caso. Nos procedimentos de investigação utilizamos a observação direta no ambiente natural e a entrevista. Os participantes da pesquisa foram: uma aluna com Necessidades Educacionais Especiais (paralisia cerebral); a professora da educanda, especialista na área da Educação Especial; e oito professores que atuam em sala de aula do Ensino Regular numa instituição pública.

Por se uma pesquisa que envolve seres humanos, o passo inicial foi o encaminhamento do projeto ao Comitê de Ética na Pesquisa da Unoeste, aprovado sob no 599/OL. Para a coleta de dados, estabelecemos os seguintes passos:

O contato da pesquisadora com a direção da escola, para solicitação de autorização para o desenvolvimento da pesquisa; contato com a mãe da aluna, para explicar o propósito da pesquisa e solicitar a assinatura do Termo de Consentimento Livre e Esclarecido (Apêndice A) para participação neste trabalho; diálogo com a professora especialista na área da Educação Especial, que desenvolve com Kar o trabalho de atendimento ao Apoio Especializado Itinerante (Apêndice B).

$\mathrm{Na}$ sequência, ocorreu o período de observações, tendo por orientação um protocolo (Apêndice C) e a aplicação de questionário a professores da escola pública estadual, os 
quais ministram aula em sala regular do Ensino Fundamental - ciclo II que atende alunos com Necessidades Educacionais Especiais (Apêndice D).

Trata-se de um estudo de caso, de natureza qualitativa, por se tratar de investigação empírica que focaliza um fenômeno contemporâneo em seu contexto de vida real (YIN, 2010).

Young (apud HELOANI; LANCMAN, 2004, p. 81) define estudo de caso como:

[...] um conjunto de dados que descreve uma fase ou totalidade do processo social de uma unidade, em suas várias relações internas e nas fixações culturais, que seja isso unidade, uma pessoa, uma família, um profissional, uma instituição social, uma comunidade ou uma nação.

O pesquisador deve ter competência para observar, obter dados e informa

ções com imparcialidade, sem se influenciar por suas próprias opiniões e interpretações. A esse respeito, Bogdan e Biklen (1994, p. 47-48) assinalam que:

$\mathrm{Na}$ investigação qualitativa a fonte direta é o ambiente natural, constituindo o investigador o instrumento principal. [...] Os investigadores qualitativos frequentam os locais de estudo porque se preocupam com o contexto. Entendem que as ações podem ser melhores compreendidas quando são observadas no seu ambiente habitual de ocorrência.

O que procuramos, com a investigação empírica, é aumentar o grau de compreensão de determinados fenômenos que afetam nossa realidade. Quanto a essa questão, Dencker e Viá (2001, p. 50) consideram que:

Para que a ciência possa produzir conhecimentos sobre a realidade ou para que possua interesse prático, é necessário que contenha elementos empíricos, pois é apenas pela experiência sensível que podemos recolher informações básicas a respeito do mundo.

Ludke e André (1986, p. 19) consideram que as características estão associadas aos estudos de casos "naturalísticos", cujas informações visam à descoberta. Esta abordagem ressalta que:

O pesquisador procura revelar a multiplicidade de dimensões presentes numa determinada situação ou problema, focalizando-o como um todo. Esse tipo de abordagem enfatiza a complexidade natural das situações, evidenciando a inter-relação dos seus componentes.

O estudo de caso pode ser visto como um conjunto de elementos em diversas situações para obter informações, aceitá-las ou descartá-las. Isto depende, antes de tudo, da profunda investigação do objeto sob as percepções e interações entre os grupos e características específicas, que são as escolhas das informações da pesquisa. 


\section{RESULTADOS}

Ao investigar como professores do Ensino Regular percebem a inclusão, verificamos que todos se mostraram favoráveis à inclusão, mas não da forma imposta. Os entrevistados argumentaram que os professores do Ensino Regular não recebem preparação para o trabalho com crianças com necessidades especiais. Essa lacuna é apontada tanto na formação inicial, quanto na continuada. Portanto, esses professores, das diversas disciplinas, alegaram não estarem devidamente capacitados para ensinar os alunos com necessidades especiais e lidar com especificidade de cada educando.

No entanto, esta pesquisa mostra aos professores interessados na inclusão, que é possível incluir alunos com Necessidades Educacionais Especiais, desde que a equipe escolar gestores, docentes, e todos que atuam no ambiente escolar - se coloque a favor da diversidade, independente do comprometimento da deficiência, construindo ações pedagógicas inclusivas para uma educação com responsabilidade social (CARNEIRO, 2005).

Quanto ao entendimento que professores do Ensino Regular têm da Tecnologia Assistiva, predomina o desconhecimento. No entanto, manifestou-se o desejo de conhecimentos, de aprimorar suas práticas e fazer uso dos recursos tecnológicos para melhor atender os alunos com necessidades especiais. É importante que o docente esteja sempre em busca, reconstruindo sua prática e mostrando respeito ao ritmo de aprendizagem de cada educando e sua especificidade.

Por meio deste estudo, foi possível acreditar nos princípios da inclusão escolar e social. Assim, colocamos em discussão o atendimento capaz de favorecer a igualdade dos alunos com Necessidades Educativas Especiais nos espaços escolares, para proporcionar a igualdade de oportunidades. Faz-se necessário, ainda, que os professores saibam lidar com as contradições entre o discurso e a prática no cotidiano.

"A educação eficaz supõe um projeto pedagógico que enseje o acesso e a permanência com êxito do aluno no ambiente escolar; que assuma a diversidade do educando, de modo a contemplar as suas necessidades e potencialidades" (BRASIL, 1999b, p. 19).

Dessa forma, torna-se essencial a atitude e a formação continuada do docente, como pesquisador que busca novas soluções para inovar suas práticas educativas, em especial, voltadas para a educação inclusiva. Vale ressaltar que as políticas públicas, no decorrer dos últimos anos, têm investido em iniciativas que favorecem interação e acessibilidade crescente às pessoas com NEE.

A pesquisa foi organizada de acordo com os seguintes temas: Tecnologia Assistiva utilizada 
pela professora no atendimento educacional especializado; contribuições da TA para crianças com necessidades especiais; percepção de professores do ensino regular da sala de apoio educacional à inclusão; entendimento de professores do ensino regular sobre Tecnologia Assistiva. As manifestações dos docentes revelam a descrença nas propostas de inclusão, sem que sejam previamente resolvidos problemas presentes no cotidiano escolar, de salas com número excessivo de alunos e a formação dos professores.

Segundo Mantoan (2003), os professores são bastante resistentes às inovações educacionais e consideram que a proposta de uma educação para todos pode ser válida, porém utópica, que não se concretiza com muitos alunos e nas circunstâncias em que os professores trabalham hoje, nas escolas, especialmente nas redes públicas de ensino.

Os professores reconhecem que a tecnologia auxilia na aprendizagem e percebem o valor desses recursos para a Educação Especial inclusiva. Como afirma Bueno (1999), o professor que possui conhecimentos tecnológicos é capaz de ministrar aulas a diferentes grupos com NEE.

Com base nos depoimentos, verificamos que os professores revelaram interesse pela Tecnologia Assistiva, pois são recursos imprescindíveis facilitadores de aprendizagens (GALVÃO FILHO, 2001). Os depoimentos mostraram que os docentes sentem-se despreparados para a utilização de Tecnologia Assistiva e, em contrapartida, têm interesse em conhecer os recursos existentes. Deixaram clara a necessidade de as políticas públicas investirem em formação continuada a todos no contexto escolar.

\section{DISCUSSÃO}

A seguir, retrataremos a percepção dos professores, considerando dois pontos de vista: Como os professores se percebem em relação à inclusão; 0 interesse deles em conhecer a tecnologia assistiva que foi organizada de acordo com os seguintes temas:

As contribuições das tecnologias para a educação de criança com necessidades especiais, constatamos que a professora especialista desenvolve ações didáticas construtivas por meio da Tecnologia Assistiva, com criatividade recorre aos recursos tecnológicos disponíveis e a adaptações que atenda as especificidades dos alunos;

Ao investigar como professores do ensino regular percebem a Inclusão, verificamos que todos dizem ser favoráveis à inclusão, mas não da forma como foi imposta. Destacam que os professores do ensino regular não recebem preparação para o trabalho com crianças com necessidades especiais. 


\section{CONCLUSÃO}

A riqueza de possibilidades ofertadas pelas tecnologias e o empenho crescente na busca de uma educação efetivamente inclusiva formam o universo da pesquisa. Com esse espírito, a pesquisa aqui relatada teve por objetivo analisar a utilização de Tecnologia Assistiva na escolarização de crianças com Necessidades Educacionais Especiais. Durante este estudo, constatamos a importância do professor capacitado para uma prática pedagógica inclusiva, capaz de conceber a aprendizagem, por meio da riqueza de possibilidades ofertadas pelas tecnologias e do interesse crescente na busca de uma educação efetivamente inclusiva.

Assim, esta pesquisa discorreu sobre um trabalho docente criativo, realizado por meio de adaptações curriculares e recursos tecnológicos. Quanto às contribuições da Tecnologia Assistiva para a educação de criança com necessidades especiais, constatamos que a professora especialista desenvolve ações didáticas construtivas de TA, com criatividade, e recorre aos recursos disponíveis ou faz adaptações deles quando necessário. No período de observação, durante a aula, a professora demonstrou-se calma, motivadora dos alunos na sua ação de ensinar a cada, com diálogos, atitudes positivas, afetividade, autoestima, criticidade, e boa interação, isso contribui para uma aprendizagem significativa ao educar na diversidade (FREIRE, 1996).

Assim, com motivação constante, a professora favorece desempenhos satisfatórios para a construção e autonomia, a fim de promover a independência de forma significativa aos alunos com Necessidades Educacionais Especiais, proporcionando-lhes acessibilidade e melhores condições para a vida diária, no âmbito educacional e profissional (BERSCH et al., 2007).

Embora ciente das dificuldades enfrentadas para a utilização dos recursos tecnológicos, a docente argumenta que não podemos deixar de reconhecer os avanços obtidos. Ainda há muito a fazer para oportunizar recursos acessíveis, especialmente de Tecnologia Assistiva, que tem ocorrido de forma processual e gradativa. Tais avanços são difíceis e lentos, mas podem se tornar possíveis, como demonstra o desenvolvimento acontecido com a criança que foi acompanhada nesta pesquisa, por meio da tecnologia e do empenho da professora especialista da sala de apoio educacional especializado.

As observações evidenciaram dados positivos na construção do conhecimento da aluna, bem como a socialização dentro do contexto escolar e virtual, visto que a aluna possui uma página de orkut, na qual interage virtualmente, superando, de alguma forma, suas limitações. Outro aspecto relevante observado nas ações da professora especialista foi que, mesmo não havendo 
recursos de acessibilidade específicos, a docente constrói adaptações simples destes, com o intuito de atender às necessidades da aluna com NEE.

Nesse caso, o sucesso no processo de inclusão do discente está ligado, essencialmente, às possibilidades de como a escola reconhece e aceita as competências dele e busca alternativas que atendam aos educandos com Necessidades Educacionais Especiais, com respeito às diferenças, como afirma Mendes (2002, p. 70):

No contexto da educação, o termo inclusão admite, atualmente, significados diversos. Para quem não deseja mudança, ele equivale ao que já existe. Para aqueles que desejam mais, ele significa uma reorganização fundamental do sistema educacional. Enfim, sob a bandeira da inclusão, estão as práticas e pressupostos bastante distintos, o que garante um consenso apenas aparente e acomoda diferentes posições que, na prática, são extremamente divergentes.

Dessa forma, torna-se essencial a atitude e a formação contínua do docente, enquanto mediador-pesquisador que busca novas soluções para inovar suas práticas educativas, em especial, voltadas para a educação inclusiva.

\section{REFERENCIAS}

$\mathrm{BERSCH}$, R. R. et al. Atendimento Educacional Especializado: Deficiência Física. São Paulo: $\mathrm{MEC} / \mathrm{SEESP}, 2007$.

BOGDAN, R.; BIKLEN, S. Investigação qualitativa em educação: uma introdução à teoria e aos métodos. As práticas escolares. Portugal: Porto, 1994.

BRASIL. Parâmetros Curriculares Nacionais - adaptações curriculares. Brasília: MEC / SEE/ SEE-SP, 1999b.

BUENO, J. G. S. Crianças com necessidades educativas especiais, política educação e a formação de professores: generalista ou especialista? Revista Brasileira de Educação Especial, Piracicaba, v. 3, n. 5, p. 7-25, 1999.

CARNEIRO, R. Aprender a educar no século XXI. Revista Brasileira de Política e Administração da Educação, Porto Alegre, v. 21, n. 1-2, p. 11-31, 2005.

DENCKER, A. de F. M.; VIÁ, S. C. da. Pesquisa empírica em ciências humanas: com ênfase em comunicação. São Paulo: Futura, 2001.

FREIRE, P. Pedagogia da autonomia: saberes necessários à prática educativa. São Paulo: Paz e Terra, 1996. (Coleção Leitura). 
GALVÃO FILHO, T. A. Educação Especial e novas tecnologias: o aluno construindo sua autonomia. Revista Integração, Brasília, ano 13, n. 23, p. 24-28, 2001.

HELOANI, R.; LANCMAN, C. Psicodinâmica do trabalho: o método clínico de intervenção e investigação. Revista Produção, São Paulo, v. 14, n. 3, p. 77-86, set./dez. 2004. Disponível em: <http://www.scielo.br/pdf/prod/v14n3/v14n3a08.pdf>. Acesso em: 12 ago. 2012.

LÜDKE, M.; ANDRÉ, M. E. D. A. Pesquisa em Educação: abordagens qualitativas. São Paulo: EPU,1986.

MANTOAN, M. T. E. Inclusão escolar. O que é? Por quê? Como fazer? São Paulo: Moderna, 2003. (Coleção cotidiano escolar).

MENDES, E.G. Desafios atuais na formação do professor de educação especial. Revista Integração, Brasília, Ano 14, n. 24, p. 22-27, 2002.

PIAGET, J. Aprendizagem e conhecimento. São Paulo: Freitas Bastos, 1974.

PIAGET, J. Psicologia e pedagogia. Tradução de Dirceu Accioly Lindoso e Rosa Maria Ribeiro da Silva. Rio de Janeiro: Forense Universitária, 1976.

VYGOTSKY, L. S. A formação social da mente. São Paulo: Martins Fontes, 1994.

VYGOTSKY, L. S. Formação social da mente: o desenvolvimento dos processos psicológicos superiores. 7. ed. São Paulo: Martins Fontes, 2007.

VYGOTSKY, L. S. Pensamento e linguagem. 2. ed. São Paulo: Martins Fontes, 1989.

WALLON, H. Psicologia e educação da criança. Lisboa: Veja Universidade, 1992.

YIN, R. K. Estudo de caso: planejamento e métodos. 4. ed. Porto Alegre: BooKman, 2010. 